\title{
Explaining value: on Orsi and Garcia's explanatory objection to the fitting-attitude analysis
}

\author{
Wlodek Rabinowicz ${ }^{1}$ (D) \\ Toni Rønnow-Rasmussen ${ }^{1}$
}

Accepted: 16 September 2020/Published online: 7 October 2020

(C) The Author(s) 2020

\begin{abstract}
Orsi and Garcia (Philos Stud, 2020, https://doi.org/10.1007/s11098-02001471-6) argue that fitting-attitude analysis of value (FA-analysis, for short) is vulnerable to an explanatory objection. On FA-analysis, for an object to be valuable is for it to be a fitting target of an attitude-a pro-attitude if its value is positive and a con-attitude if it is negative. For different kinds of value different kinds of attitudes are fitting: desire for desirability, admiration for admirability, etc. To explain the fittingness relation we therefor need to appeal to the features of the relevant attitude, but these seldom, if ever, are needed for explaining the object's value. This explanatory disparity between the analysans and the analysandum implies that FAanalysis must be incorrect. In our reply to Orsi and Garcia, we provide a refutation of their objection. We argue that the features of a fitting attitude do have a right place in the explanation of an object's value, even though they are not among the properties that make the object valuable. They help to explain this value-making relation itself.
\end{abstract}

Keywords Value · Fitting-attitude analysis · FA-analysis · Enablers · Dancy · Explanation

In a recent paper in this journal, Francesco Orsi and Andrés Garcia argue that the influential fitting-attitude analysis of value (FA-analysis, for short) is vulnerable to an objection that has not been raised before (Orsi and Garcia 2020). Their paper is thought-provoking and the objection is serious if it is correct. We are going to argue that it is not correct.

Wlodek Rabinowicz

wlodek.rabinowicz@fil.lu.se

1 Lund University, Lund, Sweden 
According to FA-analysis, for an object to be valuable is for it to be a fitting target of an attitude - a pro-attitude if the value is positive and a con-attitude if it is negative. For different kinds of value different kinds of attitudes are fitting: desire for desirability, admiration for admirability, and so on. Orsi and Garcia maintain that FA-analysis is open to an "explanatory objection": In order to explain why an object is a fitting target of a certain kind of attitude, the explanation has to refer not only to the properties of the object but also to the properties of the attitude. The properties of both are needed to explain the fit. However, to explain why an object is valuable, we seldom need to bring in attitudes; what makes an object valuable and thus explains its value are its own properties. These seldom, if ever, need to involve any reference to the properties of an attitude that fits the object. Orsi and Garcia conclude that this difference in explanations implies that being valuable is neither identical nor reducible to being a fitting target of an attitude. ${ }^{1}$

In their preliminary discussion, they distinguish between two kinds of identity. Advocates of FA-analysis might postulate conceptual identity between value concepts and concepts of fitting targets of corresponding attitudes. Or they might claim metaphysical identity between the properties picked out by those concepts, whether or not the conceptual identity obtains. In their subsequent discussion, conceptual identity recedes from view, probably because Orsi and Garcia take it to entail metaphysical identity. Consequently, refuting the latter will ipso facto refute the former. We will briefly return to this issue later on.

Orsi and Garcia state their main argument as follows:

P1 If property $P$ is identical with or reducible to the property $Q$, then any fact that explains why $Q$ is instantiated also explains why $P$ is instantiated.

P2 Not all facts that explain why the property of being a fitting target of attitudes is instantiated also explain why the property of having value is instantiated.

C Therefore, the property of having value is neither identical with nor reducible to the property of being a fitting target of attitudes. (ibid, Sect. 2)

In our discussion, we are going to focus on $\mathrm{P} 2$, which we believe is false. Orsi and Garcia support it by the following two premises:

1. Fittingness needs attitudes: The fittingness of attitudes is always explained, inter alia, by both properties of the fitting attitudes $A$ and properties of their fitting targets $O$.

\footnotetext{
1 They clarify the notion of reduction as follows: "Property $P$ reduces to property $Q$ when property $Q$ exhaustively explains property $P$. In this sense, reduction is, unlike identity, an asymmetrical relation." (ibid. Sect. 2). In a footnote, they add: "We are assuming that a reduction of one property to another does not entail that there is an identity between them." (ibid. fn. 4).
} 
2. Value does not need attitudes: Value is explained, inter alia, by the properties that make objects valuable, and while these need to include the properties of the object $O$, they need not include properties of the attitude $A$. (ibid, Sect. 2).

Orsi and Garcia state more than once that (1) and (2) taken together imply P2. To explain why an attitude fits an object we need to mention some facts about the attitude, but the object's value can be explained without them. Thus, there are facts that are needed for the explanation of the analysans in the FA analysis but are not needed for the explanation of the analysandum. If we accept both (1) and (2), we must accept P2, claim the authors. ${ }^{2}$ However, towards the end of the paper, they take this back. ${ }^{3}$ They admit that an FA advocate might accept (1) and (2) and still reject $\mathrm{P} 2$. Indeed, this should have been obvious from the outset if one considers what (2) is saying. (2) states, quite correctly, that the properties of the fitting attitude need not be included among the properties that make an object valuable. The latter are the properties of that object itself. But (2) leaves it open that the complete explanation of the object's value might need to appeal to other considerations as well. In particular, it leaves it open that the properties of the fitting attitude might also be needed for this explanation. Consequently, P2 may be false even if both (1) and (2) are true. Nevertheless, Orsi and Garcia devote most of their paper to defending (1) and (2), along with P1, the first premise of their main argument. Only very late, on the last pages of the paper, do they focus on this lacuna in their argument:

The shape of attitudes ${ }^{4}$ may have a systematic role to play in the complete explanation of value, even though not necessarily qua the properties that make objects valuable. In this way, the shape of attitudes would play an explanatory role with respect to both fittingness and value facts, and any apparent explanatory difference between fittingness facts and value facts would disappear. (ibid., towards the end of Sect. 4)

How exactly would an FA-theorist argue for this response to the explanatory objection? Orsi and Garcia provide an answer:

[...] the idea might be that the shape of an attitude plays the role of explaining why other facts or properties make an object valuable, without itself making the object valuable. The most promising model here seems to be Jonathan Dancy's notion of enabling conditions (Dancy 2004). [...] FA advocates may

\footnotetext{
${ }^{2}$ They state it in Sect. 2, immediately after introducing (1) and (2): "If claims (1) and (2) are correct, then P2 follows", and then again in the opening paragraph of Sect. 4: "once claims (1) and (2) are both established, the second premise of the explanatory objection P2 is also established."

3 Indeed, already in Sect. 2, Orsi and Garcia indirectly warn the reader that the entailment from (1) and (2) to P2 might be questioned. As they point out, FA advocates might argue that "FA can actually accommodate both claims (1) and (2)." But they immediately add: "we argue in Sect. 4 that a version of FA that tries to accommodate both claims (1) and (2) (rather than reject either) is highly problematic."

4 By the "shape" of an attitude, they mean its properties, or perhaps, more specifically, those of its properties that together make it fit certain objects. (Cf. Sect. 4, first paragraph.)
} 
[...] say that the shape of an attitude enables other facts to play the valuemaking role; for example, the shape of admiration may enable other facts, e.g. facts about the artistic qualities of a painting, to make a given painting admirable. (ibid., Sect. 4)

As is well known, Dancy (2004, see especially pp. 85-88) distinguishes between the relations of supervenience and resultance. As applied to value, the value of an object supervenes on a broad range of facts-all the facts on which this value in a broad sense depends ${ }^{5}$ - but the resultance base of value only contains the properties of the object that 'make' it valuable, or 'give' it value. (2) does not really make the claim that "value does not need attitudes". It makes a much weaker claim that value does not need facts about attitudes as value-makers. It might still need them in another capacity - as parts of its supervenience base. Some of the facts on which the object's value supervenes, but which are not part of its resultance base, are enablers: these facts enable the elements of the resultance base to be value-makers. The idea Orsi and Garcia now consider is that in the complete explanation of an object's value, which brings in its whole supervenience base, facts about attitudinal properties might need to be invoked as such enablers. The properties of an object that make it, say, admirable (desirable, delightful, etc.) play this value-making role in part because of the properties of the corresponding attitude (admiration, desire, delight, ...). That is, the explanation of why the properties of an object make it, say, admirable, requires mention of the properties of admiration; otherwise the explanation is incomplete. ${ }^{6}$

How exactly can facts about the properties of an attitude be such enablers? Orsi and Garcia do not make it clear. One possibility would be that attitudes come with inherent standards - say, admiration comes with criteria that specify what is to be admired, or perhaps with paradigmatic examples-and that because of these standards some properties of objects (in virtue of which the objects satisfy or approximate the standards) become value-makers. Because of the inherent standards of admiration certain properties of an object make it admirable. ${ }^{7}$

\footnotetext{
${ }^{5}$ Dancy accounts for supervenience in the standard way: in terms of invariance. Supervening facts are invariant across all possible situations that don't differ with regard to the subvening facts, i.e., with regard to the supervenience base.

${ }^{6}$ Attitudes might also be important for the explanation of value in another way. On value projectivism, attitudes are constitutive grounds of value: our pro- and con-attitudes project values on the world. Indeed, on this view, our attitudes in the actual world project values on other possible worlds as well. The attitudes that form the constitutive grounds of value are not part of its supervenience base. While the latter must be present in a possible world in which an object under consideration has value, constitutive grounds of its value must instead be present in the actual world - the world from which projection is being made. For this notion of constitutive grounds, see Rabinowicz and Österberg (1996), Rabinowicz and RønnowRasmussen (2000), Rønnow-Rasmussen (2011, Sects. 1.8-1.9), Fritzson (2014) and Garcia and Werkmäster (2018). Orsi and Garcia mention this potential constitutive role of attitudes in a footnote (fn 24), but quite rightly point out that it presupposes a contentious constructivist conception of value-a subjectivist view that is compatible with FA-analysis but certainly is not implied by it.

${ }^{7}$ That attitudes have inherent standards is a view defended by McHugh and Way (2016). Orsi and Garcia mention this view earlier in the paper, in Sect. 3, but there the issue is how to understand the fittingness of attitudes and not their role as enablers.
} 
But a more obvious and less contentious option is that the properties of an attitude enable the properties of the object to be value-makers simply because they determine the nature of the value in question. Clearly, admirability is a value whose nature in part is determined by what the attitude of admiration consists in. Likewise, the nature of desirability in part is determined by the constitutive properties of desire, and so on. The particular relation of value-making, which obtains between the object's properties and the value it has, must depend on the nature of the value in question. Consequently, the properties of the attitude, which determine the nature of the corresponding value, have an enabling role with respect to the value-making relation itself. As such, they need to be mentioned in the complete explanation of the object's value.

It should be added that this is not the kind of enabling that Dancy had in mind. His enablers typically are empirical facts about the context in which the object is located. These facts indirectly affect the object: they cause it to possess certain contingent relational properties (such as being located in a particular context). These properties do not make the object valuable but they enable some of its other features to make it valuable. By contrast, the essential properties of an attitude do not affect the object; instead, they enable the value-making relation itself, by determining the nature of the value in question. Nor are facts about essential properties of an attitude empirical, in contrast to Dancy's enablers. Using the same term, "enablers", for both these kinds of conditions might therefore engender confusion, unless the distinction between them is firmly kept in mind. ${ }^{8}$

Now, how do Orsi and Garcia respond to this criticism of their explanatory objection? They offer two lines of defence. The first line consists in the claim that bringing in properties of attitudes as enablers involves a substantive axiological commitment and thus carries a significant theoretical cost:

[T] his move would violate the substantive neutrality that is understood to be a sine qua non of FA. [...] By including properties of attitudes in the explanation of value, FA would be wedded to a particular view in substantive axiology, albeit one about specific enabling conditions rather than about specific value-making properties. This would be a significant theoretical cost.

(Sect. 4)

This contention might seem puzzling. Why would treating the essential properties of, say, admiration as enabling conditions of admirability commit FA-analysis to any substantive axiological view? Would it commit this analysis to some substantive evaluation? Possibly, it is here that the confusion regarding different kinds of enabling rears its head. It is true that Dancy's examples of enablers amount to substantive evaluations. Consider, for instance, his much-discussed example of a funny joke that wouldn't have been funny if a certain empirical fact about the context hadn't obtained: if the butt of the joke had not been present. This is not what makes the joke funny, but it enables its other features to make it funny (Dancy 2004, p. 172). That the joke wouldn't have been funny if the person at whose expense it is

\footnotetext{
${ }^{8}$ We are indebted to a referee for pressing this important point.
} 
made hadn't been present is clearly a substantive evaluation on Dancy's part. Perhaps Orsi and Garcia have been led by these examples to believe that every claim about enablers involves a similar substantive commitment. Or perhaps they were led to this belief by an analogy: Perhaps they thought that all claims about what enables an object's value must be as substantive as claims about what makes the object valuable? But whatever the reason, surely this idea that all claims about enabling conditions must be substantive evaluations is wrong. The appeal to the essential properties of admiration as enablers of admirability is not substantive in this way at all. It is a purely conceptual claim.

Orsi and Garcia seem to realize the weakness of this line of their defence. Although they don't quite admit it and still assume that an FA-advocate might "agree that understanding shapes of attitudes as enablers is a substantive view", they recognize that this view could be claimed to be "neutral enough". Adherents of FA analysis could insist that treating the shape of admiration as an enabler with regard to admirability is "compatible with any first-order view about what is admirable or about what makes something admirable." (Sect. 4)

Orsi and Garcia are not happy with this expected response:

we believe this claim [of neutrality] to be questionable (and anyway in need of thorough examination. (ibid.)

They do not explain why the neutrality claim is questionable. Instead, they move at this point to their second line of defence:

Suppose it were true that the full explanation of something being admirable, enviable, fearsome etc. owed something to the shape of admiration, envy, fear etc. It would still need to be shown that the full explanation of the rather different property of being good (bad, better etc.) simpliciter owes something to the shape of attitudes. (Sect. 4)

Indeed, in the course of developing this line, Orsi and Garcia go even further in what they are prepared to grant. They now admit that for such 'response-dependent' values as admirability, desirability, enviability, etc., FA-analysis is "a philosophical (metaphysical or conceptual) articulation of a semantic platitude":

in English "admirable", quite simply means "a fitting (or cognate terms: appropriate, worthy etc.) target of admiration", and the same mutatis mutandis for other response-mentioning value terms. There is hardly any lexical room for anyone to disagree with a version of FA restricted to such value properties. (Sect. 4)

This passage is in one way uncontroversial but in another way might seem surprising. It is uncontroversial in what it says. "Admirable" just means "fitting (worthy, ...) to be admired". Likewise, "desirable" just means "fitting (worthy, ...) to be desired", and so on. But at the same time the passage might seem surprising, given that it comes so late in the paper. Orsi and Garcia now seem to admit that FAanalysis is correct with regard to a very broad range of values: admirability, desirability, enviability, delightfulness, etc. It is true that such thick values are not what interests the authors most. Already in the Introduction they state (in a footnote; 
see fn. 2) that their "focus in this article is on the FA analysis of thin value properties." Still, does it mean that they themselves agree that the explanatory objection is simply misguided when it comes to all 'response-dependent' values?

Or do they think that the correctness of the analysis does not yet imply that the properties picked out by the analysans and the analysandum are identical? Admittedly, analytical truths not always are metaphysically necessary. On our prescientific concept of water, water is a transparent, tasteless, drinkable liquid that boils when heated and turns into ice when chilled. However, this characterization of water was metaphysically contingent even when it still was analytic. There is no necessity in water being transparent or boiling when heated. Nor is there any necessity in the opposite direction: in a 'Twin Earth'-like possible world, the transparent, tasteless liquid that people drink isn't water. ${ }^{9}$ But the relation between concepts that appear in FA-analysis does not seem to be like this: it does not seem to be hostage to metaphysical contingencies. To be sure, other things might be admirable in other possible worlds. Possibly, even, the standards of admirability can change. But then it will be these other things, which satisfy these potentially different standards, that in those worlds it will be fitting to admire. So, it is difficult to argue that FA-analysis is correct but the properties picked out by its analysans and analysandum still are distinct. And, anyway, Orsi and Garcia do not come with any suggestions along these lines.

Does FA-analysis then go well together with the idea that facts about attitudes are a kind of enablers with regard to value? We think so. Both the properties of an attitude and the properties of its object are included in the resultance base of the fittingness relation between the attitude and the object. The value of the object is not this relation, though. It is not a relation at all; it is a property of the object. On FAanalysis, it is a relational property: the object has it in virtue of it being a target of a fitting attitude of a certain kind. ${ }^{10}$ The relation on which this property is grounded does not of course connect the object to any concrete token of an attitude in question (indeed, no such token might be in existence); it connects it to an abstract attitude type. What, then, is the resultance base of value? Unlike the resultance base of the fittingness relation, it only includes properties of the valuable object (the ones that make it a fitting target of a pro-attitude), while the properties of the pro-attitude that would fit that object instead play the role of enablers.

\footnotetext{
9 But how can it be if "water" is defined as "a transparent ... liquid that ..."? The answer is that this definition contains an implicit reference to how things actually are: "(the stuff that, as things actually are, is) a transparent ...liquid that ...". For another well-known example, consider "One meter $=$ the length of the standard meter in Paris". This identity statement is only contingently true (if heated, the standard meter would become longer than one meter), but it was for a long time analytic, before new official definitions of a meter have come to be accepted. For a discussion of the relationship between analyticity (= truth in virtue of meaning) and necessity, in the framework of possible-worlds semantics, see Rabinowicz (2010).

${ }^{10}$ Alternatively, if one follows Scanlon's lead, value is a second-order property: the property of having (first-order) properties that make their bearer a fitting target of a certain kind of a pro-attitude (Cf. Scanlon 1998 , Ch. 2. Scanlon puts it in terms of reasons for a pro-attitude rather than in terms of what would make it fitting, but this difference doesn't affect the main idea of value as a second-order feature.)
} 
This is so at least when it comes to 'response-dependent' values. But Orsi and Garcia ask the reader to consider goodness (or badness) simpliciter. For that central value, they claim, FA-analysis doesn't seem to hold.

Being good simpliciter is being good in an unqualified way. It can be contrasted with being good for someone, being a good exemplar of its kind ("a good watch"), being good as a means, being contributively good, etc. Orsi and Garcia provide examples of what they have in mind and the examples suggest that they mean something like "goodness for its own sake":

Value simpliciter is the property that hedonists ascribe to pleasure, preferentists to preference satisfaction, Kantians (arguably) to the good will, objective list theorists to a number of things like knowledge, friendship, beauty, and so on. (Sect. 4)

They envisage two options for an FA-advocate at this point: One is to reject that there is such a value as goodness simpliciter and the other is to accept that FAanalysis here meets its limit. The first option is counter-intuitive and, in any case, very radical:

One would have hoped FA to avoid having to take a stand on what kinds of value properties there are. (ibid.)

While the second option makes the FA-approach much less attractive:

One would have hoped FA to be ambitious enough to account for the kinds of value properties that have been the subject of traditional axiological debates. (ibid.)

We agree. But there is a third option Orsi and Garcia do not consider. We are taking it now for granted that they accept the FA analysis for values that are manifestly response-dependent. But then the natural option for FA-advocates to try out is to extend this format of analysis to goodness simpliciter.

In this case, FA-advocates cannot appeal to lexical considerations, but they can point out that even for this value it is very plausible to accept a bi-conditional that connects it with fitting pro-attitudes, or-more generally-with fitting proresponses, which may be partly attitudinal and partly behavioral ${ }^{11}$ :

An object is good simpliciter (or "for its own sake") if and only if it is a fitting target of approval and, if applicable, of furthering, for its own sake. ${ }^{12}$

Here "approval" stands for a 'thin' attitude of favoring. It differs from such 'thick' pro-attitudes as admiration, awe, enjoyment, etc. How to analyze it in more detail is an important issue, but one we will not attempt to resolve in this short discussion

\footnotetext{
11 That FA-analysis, in order to be satisfactory, requires broadening of fitting pro-responses to cover not only attitudes but also behaviors has been argued for in Rabinowicz and Rønnow-Rasmussen (2004).

12 As has been pointed out by a referee, promotion of a particular good might sometimes be impossible. Also, it might sometimes conflict with other goals we ought to pursue.
} 
note. ${ }^{13}$ "Furthering" is meant to refer to behavioral pro-responses, which may vary depending on what kind of object we are talking about: Good states of affairs call for realization, good goals should be pursued, good options are worthy of choice, good things deserve to be brought into existence if they don't exist and to be protected if they do.

Given that the bi-conditional above is so plausible, as we take it to be, FA advocates might well go on and suggest that the properties picked out by its lefthand and right-hand sides are identical. To be good simpliciter just is to be approvable and promotable, for its own sake. This suggestion demystifies the normative compellingness of goodness simpliciter: its inherent prescriptivity. ${ }^{14,15}$ And the suggestion can be also argued for on the grounds of simplicity. It allows us to unify the field of values, to make them all amenable to the same FA-format of analysis.

Given this account, just as in the case of the manifestly response-dependent values, facts about fitting attitudes and, more generally, about fitting responses are needed in the complete explanation of goodness simpliciter. These facts enable the value-making relation between the properties of an object and its goodness simpliciter. They do it by determining the nature of that value: in particular, its normative implications.

We think, therefore, that the explanatory objection to FA-analysis is not tenable, after all.

Acknowledgements We wish to thank Andrés Garcia for helpful discussion and anonymous referees for insightful comments and suggestions.

Open Access This article is licensed under a Creative Commons Attribution 4.0 International License, which permits use, sharing, adaptation, distribution and reproduction in any medium or format, as long as you give appropriate credit to the original author(s) and the source, provide a link to the Creative Commons licence, and indicate if changes were made. The images or other third party material in this article are included in the article's Creative Commons licence, unless indicated otherwise in a credit line to the material. If material is not included in the article's Creative Commons licence and your intended use is not permitted by statutory regulation or exceeds the permitted use, you will need to obtain permission directly from the copyright holder. To view a copy of this licence, visit http:// creativecommons.org/licenses/by/4.0/.

Funding Open access funding provided by Lund University.

\footnotetext{
13 Another important issue that would need closer examination is the question of what it is that different pro-attitudes, whether thin or thick, have in common. What is it that makes them all "pro"? We are indebted to a referee for pressing this point. But again, it is not a question that we can attempt to answer in this discussion note.

14 Cf. Rabinowicz and Rønnow-Rasmussen (2004). We assume that fittingness is a normative notion: when fitting, pro-responses are 'called for', as the saying goes. Note, though, that the prescriptivity of goodness appears to be relatively mild: it is best understood as a recommendation, rather than as a strict demand.

15 A referee has objected that this prescriptivity of value would be satisfactorily accounted for if one just accepted the bi-conditional as a conceptual truth, without taking it to be an analysis of value. We don't agree. If it is not an analysis, then the prescriptivity of value, while acknowledged, still remains a mystery.
} 


\section{References}

Dancy, J. (2004). Ethics without principles. Oxford: Oxford University Press.

Fritzson, F.-A. (2014). Value grounded on attitudes: Subjectivism in value theory (doctoral dissertation). Lund: Media-Tryck.

Garcia, A., \& Werkmäster, J. (2018). Subjectivism and the framework of constitutive grounds. Ethical Theory and Moral Practice, 21, 155-167.

McHugh, C., \& Way, J. (2016). Fittingness first. Ethics, 126, 575-606.

Orsi, F., \& Garcia, A. (2020). The explanatory objection to the fitting-attitude analysis of value. Philosophical Studies. https://doi.org/10.1007/s11098-020-01471-6.

Rabinowicz, W. (2010). Analyticity and possible-world semantics. Erkenntnis, 72, 295-314.

Rabinowicz, W., \& Österberg, J. (1996). Value based on preferences: On two interpretations of preference utilitarianism. Economics and Philosophy, 12, 1-27.

Rabinowicz, W., \& Rønnow-Rasmussen, T. (2000). A distinction in value-Intrinsic and for its own sake. Proceedings of the Aristotelian Society, 100, 33-51.

Rabinowicz, W., \& Rønnow-Rasmussen, T. (2004). The Strike of the demon: On fitting pro-attitudes and value. Ethics, 114, 391-423.

Rønnow-Rasmussen, T. (2011). Personal value. Oxford: Oxford University Press.

Scanlon, T. M. (1998). What we owe to each other. Harvard: Harvard University Press.

Publisher's Note Springer Nature remains neutral with regard to jurisdictional claims in published maps and institutional affiliations. 